Zorica Djordjević

Mirko Blagojević

Snežana Vulović

Danijela Nikolić

Saša Jovanović

DOI: $10.21278 /$ TOF.41204

ISSN 1333-1124

eISSN 1849-1391

\title{
AN INVESTIGATION INTO HYBRID ALUMINIUM/COMPOSITE CARDAN SHAFT
}

\begin{abstract}
Summary
It is a well-known fact that natural resources are becoming increasingly scarce. Consequently, whenever possible in the machine element manufacture, metallic materials should be replaced with new artificial materials. This paper studies the possibility of replacing two cardan shafts of a truck TURBO ZETA $85.14 \mathrm{~B}$ with one shaft made of aluminium and a composite material, while the basic requirements concerning the given load transfer and fundamental natural frequencies remain satisfied.
\end{abstract}

Key words: $\quad$ composite materials, hybrid drive shaft, natural frequency, strain gauges

\section{Introduction}

In addition to the introduction of the new design and manufacturing technologies, modern machine construction requires an application of new materials with higher specific strength and hardness compared to traditional materials. These criteria are met by composite materials, whose values of impact resistance, strength and hardness, and particularly resistance to fatigue, vibratory and acoustical loads are higher than the values of the known metals and alloys. Composite materials consist of different components combined with the aim to get materials with superior mechanical properties. These mechanical properties may vary and they depend on the choice of components, their quantity, spatial alignment and orientation within the material. Because of their good mechanical properties, composite materials are increasingly used in the manufacture of transmission shafts.

A number of investigators have studied drive shafts made of composite materials. In the paper [1], the authors study the calculation and methods for manufacturing a hybrid aluminium/composite drive shaft for an automobile. The weight of the manufactured hybrid drive shaft is reduced by $75 \%$ compared to a conventional steel shaft, while the load carrying capacity and natural fundamental frequencies are increased.

The paper [2] analyses the effects of boundary conditions, fibre orientation and stacking sequence on the mechanical behaviour of composite drive shafts. 
Gubran H.B.H and Gupta K. [3] carried out theoretical and experimental studies on deflection and cross-section deformation of tubular composite shafts subjected to the point static loading.

The paper [4] presents a comprehensive approach to designing drive shafts for applications in the automotive industry. It studies two important aspects of the drive shaft design - the design of a composite shaft tube and the design of an adhesively bonded tubular joint between the yoke and the tube.

In the paper [5], dynamic performance and cross-section deformation of shafts made of metals (steel and aluminium), composites (CFRP and GFRP) and hybrids of metals and composites have been studied. A layered finite degenerated shell element with transverse shear deformation and dynamic behaviour is employed. The results obtained show that improvements in dynamic performance and reduction in the cross-section deformation of hybrid shafts compared to metallic and composite shafts are possible.

Badie et al. [6] studied the effects of fibre orientation angles and stacking sequence on the torsional stiffness, natural frequency, buckling strength, fatigue life and failure modes of composite tubes.

Mutasher [7] and Abu Talib et al. [8] have recently studied the design and manufacture of hybrid metallic/composite drive shafts. They proposed the use of a combination of highmodulus (HM) and high-strength (HS) carbon fibre reinforced epoxy plies in order to benefit from the advantages of each fibre type.

The paper [9] analyses shafts made from a combination of aluminium and different composite materials - carbon fibre/epoxy, glass fibre/epoxy, and aramid fibre/epoxy. The influence of these materials on the twist angle values and critical torques that impair the shaft stability has also been discussed. Finally, an experimental analysis of the shaft that exhibited the best properties (carbon fibre/epoxy) has been performed.

This paper analyses the possibility to replace a two-piece steel cardan drive shaft of a truck with a one-piece hybrid aluminium/composite shaft. The analysis was performed both numerically (by applying FEM) and experimentally (by using strain gauges).

\section{Advantages of composite materials}

High values of specific stiffness $E / \rho$ ( $E$ - tensile modulus, $\rho$ - density) give composite materials a huge advantage over traditional materials because components of much lower weight that fully meet the load carrying capacity criteria can be manufactured. This is very useful in the cases when the weight of components is of vital importance.

Composite materials belong to the group of anisotropic materials and therefore their mechanical properties greatly depend upon the angle of measurement of individual properties. Their strength significantly depends upon the orientation of the reinforced fibres whereas the longitudinal tensile strength greatly exceeds the transverse strength.

Unlike metals, composite materials are not prone to plastic deformation. This practically means that only elastic deformations will occur when the materials are subjected to the action of external forces. As for fatigue, composites are fundamentally different from metals. While metals show fatigue failure only in one way (by cracking), composites fail in different failure modes (matrix - fibre separation, delamination, fibre fracture, matrix cracking, etc.). One of the essential properties of composite materials is their relatively high load carrying capacity even after a partial damage. This is due to the load transfer in a large number of fibres.

Some of the major advantages of composite over traditional materials are the following:

- greatly reduced weight of the structure (even up to $50 \%$ compared to the steel structure of the same dimensions), 
- high strength and hardness - tensile strength of composites is several times higher than of steel or aluminium,

- good impact strength,

- increased resistance to fatigue, wear vibration and acoustic loads,

- greatly reduced number of the structure component parts,

- possibility to make parts of complex shape,

- extremely uniform absorption of vibrations, etc.

\section{Numerical analysis of the composite shaft}

With complex problems such as these and with differential equations that can hardly be solved analytically, it is a common practice to apply specific hypotheses and simplifications in order to solve the equations numerically. One way of solving partial differential equations is the application of the finite element method (FEM), which is nowadays becoming increasingly efficient due to the use of modern computers.

For hollow shafts with a low wall thickness, as in the case of composite shafts, shell shape elements are most commonly used (e.g. lamina shaft in orthotropic multiple layer shell shape).

The main characteristic of multiple layer shells (Figure 1) is that high stiffness of the shell structure can be achieved with adequate fibre orientation, material direction and with low thickness. Basic hypotheses applied to the kinematic deformation of an isotropic shell can also be applied to orthotropic shells.
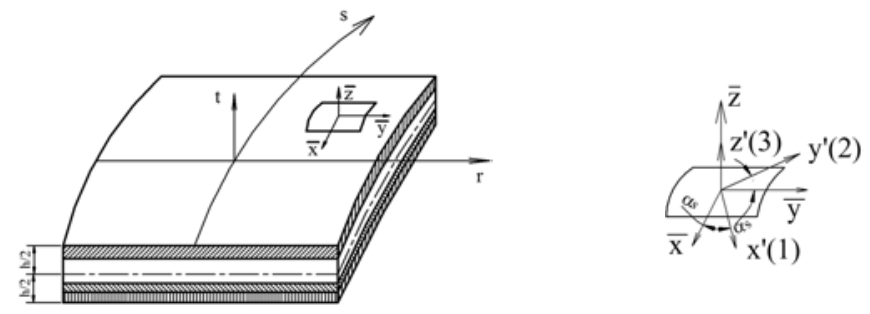

Fig. 1 Multiple layer shells

All values are calculated layer by layer, by formulating finite elements of the multiple layer shell [10]. In this case, the basic values such as motion and deformation are calculated in the material coordinate system $x^{\prime}, y^{\prime}, z^{\prime}$.

We get:

$$
\varepsilon^{\prime}=\boldsymbol{T}^{\varepsilon} \bar{\varepsilon}=\boldsymbol{T}^{\prime} \varepsilon \boldsymbol{T}^{\varepsilon} \varepsilon=\overline{\boldsymbol{T}}^{\varepsilon} \varepsilon
$$

where $\boldsymbol{\varepsilon}$ stands for the deformation in the global coordinate system $x, y, z, \bar{\varepsilon}$ and $\boldsymbol{\varepsilon}^{\prime}$ are deformations in the system $\bar{x}, \bar{y}, \bar{z}$ and $x^{\prime}, y^{\prime}, z^{\prime}$, respectively, $\boldsymbol{T}^{\varepsilon}$ is the transformation matrix, and $\boldsymbol{T}^{\boldsymbol{\varepsilon}}$ is the total transformation matrix that corresponds to the transformation of deformations between the global coordinate system $x, y, z$ and the local system $\bar{x}, \bar{y}, \bar{z}$.

The stiffness matrix of the layer $s$ is [10]:

$$
\boldsymbol{K}^{\mathrm{s}}=\int_{V^{s}} \overline{\boldsymbol{p}}^{\mathrm{sT}} \overline{\boldsymbol{D}}^{\mathrm{s}} \overline{\boldsymbol{p}}^{\mathrm{s}} d V
$$

here, $\overline{\boldsymbol{p}}^{s}$ - the interpolation matrix and $\overline{\boldsymbol{D}}^{s}$ - the tensile matrix of this layer are given in the material coordinate system $x^{\prime}, y^{\prime}, z^{\prime}$. In practice, the numerical integration by the layer volume $V^{s}$ is done and the stiffness matrix $\boldsymbol{K}$ is given as the sum of the layers' stiffness: 


$$
\boldsymbol{K}=\sum_{s} \boldsymbol{K}^{\mathrm{s}}=\sum_{s} \int_{V^{s}} \overline{\boldsymbol{p}}^{\mathrm{sT}} \overline{\boldsymbol{D}}^{\mathrm{s}} \overline{\boldsymbol{p}}^{\mathrm{s}} d V
$$

The tension at the material point in the layer $\mathrm{s}$ is given as:

$$
\boldsymbol{\sigma}^{\prime}=\overline{\boldsymbol{D}}^{\mathrm{s}} \boldsymbol{\varepsilon}^{\prime},
$$

where the tension $\sigma^{\prime}$ corresponds to the coordinate system $x^{\prime}, y^{\prime}, z^{\prime}$. The force vector in nodes, $F^{u}$, has the following form:

$$
\boldsymbol{F}^{\mathrm{u}}=\sum_{s} \int_{V^{s}} \overline{\boldsymbol{p}}^{\mathrm{sT}} \boldsymbol{\sigma}^{\prime} d V
$$

Hollow shafts with a small wall thickness (e.g. composite shafts) are analysed using shell elements, particularly if the shafts are laminated or if they are in the shape of an orthotropic multi-layer shell [10], [11], [12].

\section{Analysis of the stress state of the hybrid Al/composite cardan shaft}

This paper studies a real shaft of a truck TURBO ZETA 85.14B. In fact, it studies a possibility of using one shaft made of aluminium and composite materials instead of two steel cardan shafts (the front cardan shaft and the back cardan shaft (Figure 2)), while the basic requirements concerning the given load transfer and fundamental natural frequencies are satisfied.
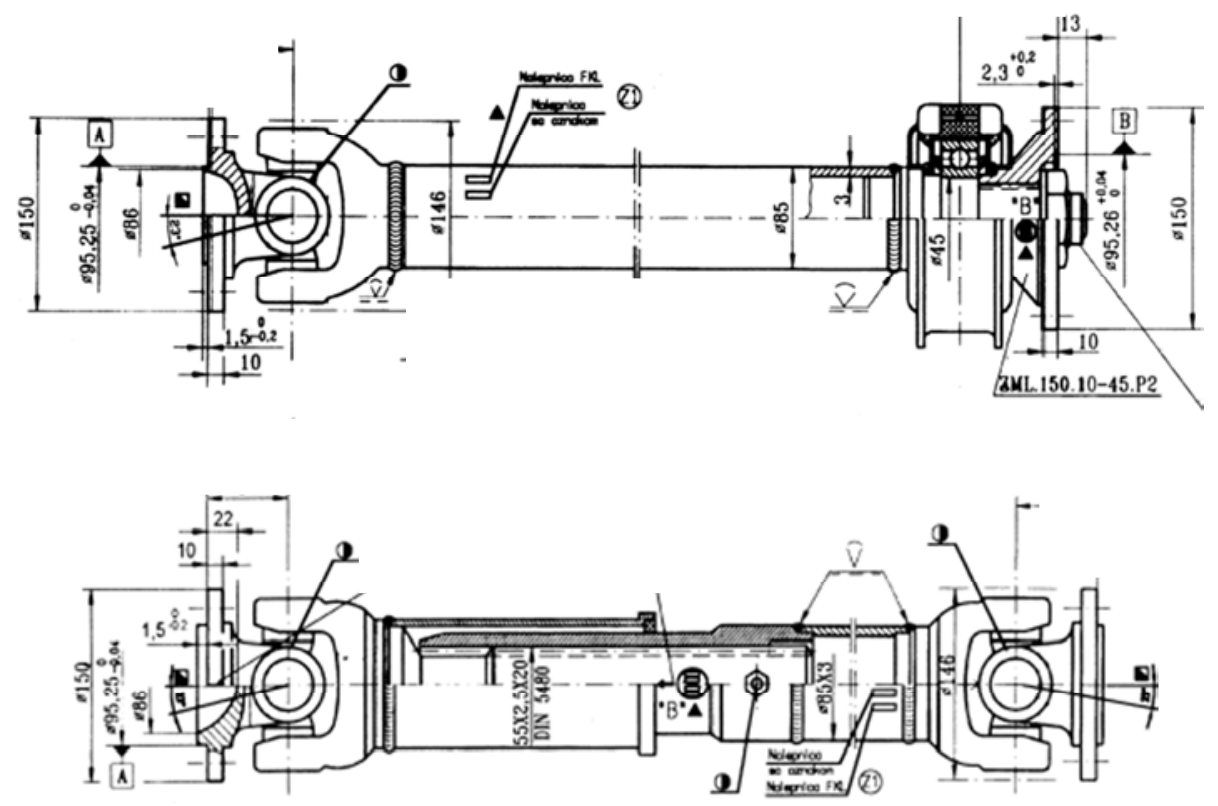

Fig. 2 The front and the back cardan shaft of the truck TURBO ZETA

The basic dimensions of the analysed hybrid Al/composite shaft [11] are the following: the shaft length is $1.35 \mathrm{~m}$, and the mean radius of the shaft is $0.041 \mathrm{~m}$. The length of the onepiece hybrid $\mathrm{Al} / \mathrm{composite}$ drive shaft corresponds to the distance between the cardan forks of the two-piece steel shaft given in Figure 2.

It has been demonstrated that a combination of aluminium and a composite material gives good results, e.g. in [7], [8]. The shafts analysed here were obtained for the case of the combination of aluminium and carbon fibre (USN150)/epoxy composites. Galvanic corrosion 
between carbon fibres and aluminium is a significant problem. The problem can be prevented by applying a layer of fibreglass around the Al tube.

Table 1 shows basic properties of this composite material.

Table 1 Basic properties of the composite material

\begin{tabular}{|c|c|c|c|c|c|c|c|c|c|c|c|}
\hline Material & $\begin{array}{c}E_{1}, \\
\mathrm{GPa}\end{array}$ & $\begin{array}{c}E_{2}, \\
\mathrm{GPa}\end{array}$ & $\begin{array}{c}G_{23}, \\
\mathrm{GPa}\end{array}$ & $\begin{array}{c}G_{12}, \\
\mathrm{GPa}\end{array}$ & $v_{12}, v_{13}$ & $\begin{array}{c}\rho, \\
\mathrm{kg} / \mathrm{m}^{3}\end{array}$ & $\begin{array}{c}t_{\mathrm{ply}}, \\
\mathrm{mm}\end{array}$ & $\begin{array}{c}S_{1}^{t}\left(S_{1}^{c}\right), \\
\mathrm{MPa}\end{array}$ & $\begin{array}{c}S_{2}^{t}\left(S_{2}^{c}\right), \\
\mathrm{MPa}\end{array}$ & $\begin{array}{c}S_{23}, \\
\mathrm{MPa}\end{array}$ & $\begin{array}{c}S_{13}, \\
\mathrm{MPa}\end{array}$ \\
\hline $\begin{array}{c}\text { Carbon } \\
\text { fibre/epoxy } \\
\text { composite }\end{array}$ & 131.6 & 8.20 & 3.5 & 4.5 & 0.281 & 1550 & 0.125 & $\begin{array}{c}2000 \\
(-1400)\end{array}$ & $\begin{array}{c}61 \\
(-130)\end{array}$ & 40 & 70 \\
\hline
\end{tabular}

In Table 1, the following notation is used: $E_{1}-$ longitudinal modulus; $E_{2}$ - transverse modulus; $G_{12}, G_{23}$ - shear modulus; $v_{12}-12$ - direction Poisson's ratio; $v_{13}-13$ - direction Poisson's ratio; $\rho$-density; $t_{\mathrm{ply}}$ - composite layer thickness, $S_{1}{ }^{t}, S_{1}{ }^{c}-$ longitudinal tensile and compressive strength, $S_{2}{ }^{t}, S_{2}{ }^{c}-$ transverse tensile and compressive strength, $S_{13}, S_{23}-$ shear strength.

Properties of the aluminium tube that was used together with the composite material in the manufacture of hybrid aluminium/composite shafts are given in Table 2. Table 2 shows also the properties of the material and the wall thickness of the steel shaft.

Table 2 Basic properties of aluminium tube (6061-T6) and steel tube (C40E)

\begin{tabular}{|c|c|c|c|c|c|}
\hline Material & $E, \mathrm{MPa}$ & $G, \mathrm{MPa}$ & $\rho, \mathrm{kg} / \mathrm{m}^{3}$ & $R_{\mathrm{e}}, \mathrm{MPa}$ & \\
\hline Aluminium & 72000 & 27000 & 2695 & 325 & 2.5 \\
\hline Steel & 210000 & 83000 & 7830 & 460 & 3.5 \\
\hline
\end{tabular}

The analysed shaft was modelled using linear isoparametric square shell finite elements. It was divided into 80 elements in the axial and 50 elements in the circular direction. For the numerical analysis, the shaft was fixed at one end while the torsion momentum acted on the other loose end. The shaft was tested for the maximum value of the static torque of 5,000 Nm. NX Nastran software was used for the analysis.

The composite part of the shaft consisted of 8 layers of carbon fibre/epoxy resin with the fibre orientation angle of $\pm 45^{\circ}$. Since the bonding thickness between the aluminium tube and the composite layer was very small when co-cured under pressure, perfect bonding between the aluminium tube and the composite layer was assumed for the finite element analysis. The values of the stress due to torsion in the aluminium and the highest loaded composite layer are given in Figures 3 and 4, respectively. 


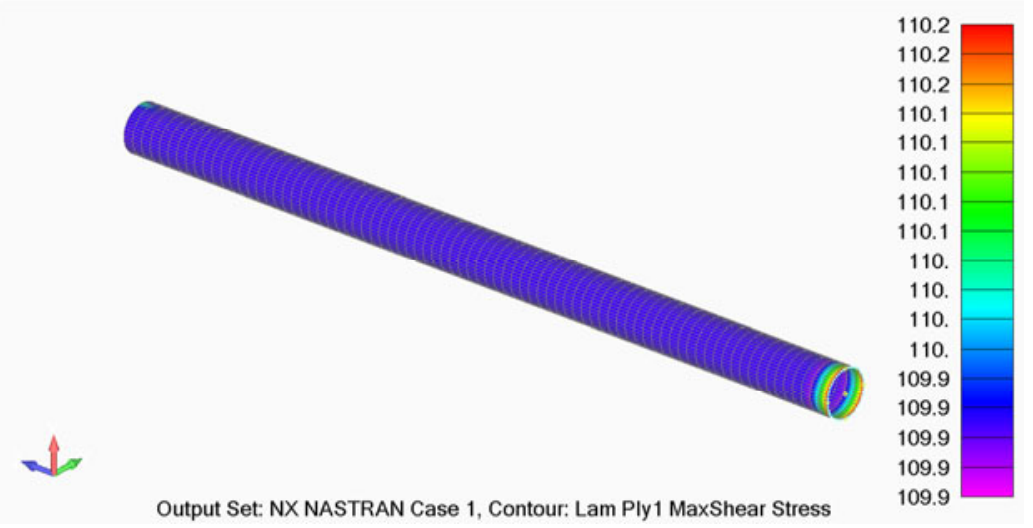

Fig. 3 Stresses due to torsion in the aluminium layer of the hybrid $\mathrm{Al} /\left[ \pm 45_{\mathrm{USN}, 4}\right]$ shafts, $\mathrm{MPa}$

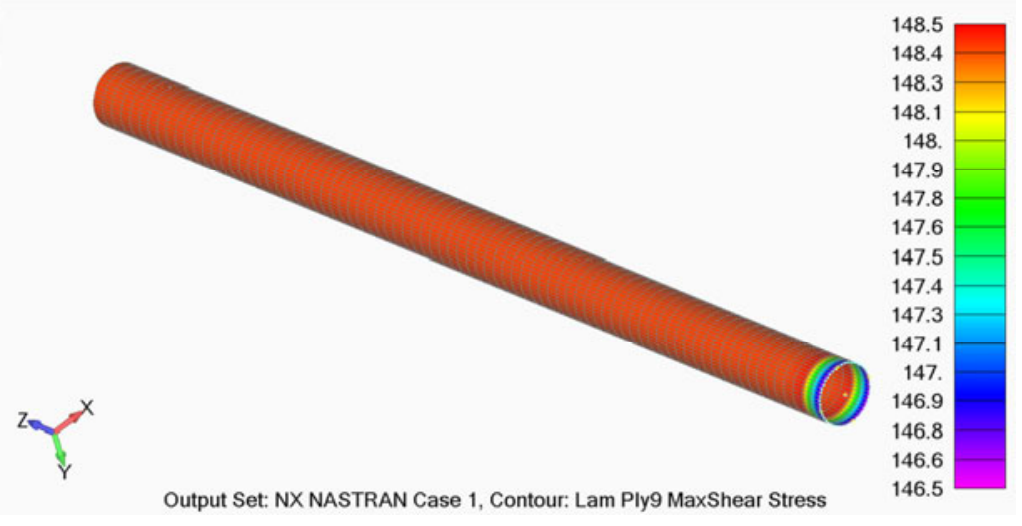

Fig. 4 Stresses due to torsion in the highest-loaded composite layer of the hybrid $\mathrm{Al} /\left[ \pm 45_{\mathrm{USN}, 4}\right]$ shafts, MPa

According to the Tsai-Wu failure criterion, in order for the failure not to occur, the failure initiation coefficient should be $F I \leq 1$ [13]. The values of the failure initiation coefficient $F I$ can be determined by applying the finite element method. The obtained values of the FI coefficient for the analysed hybrid drive shaft are given in Table 3. Based on Table 3 , it can be concluded that the composite layer can endure much higher loads than the one analysed here, because the value of the failure coefficient FI for each layer, even the highest loaded one, is much lower than 1.

Table 3 FI values for each composite layer of the hybrid Al/USN150 carbon fibre/epoxy composite shaft

\begin{tabular}{|c|c|c|c|c|c|c|c|c|}
\hline Layer & 1 & 2 & 3 & 4 & 5 & 6 & 7 & 8 \\
\hline$F I$ & 0.219 & 0.220 & 0.221 & 0.223 & 0.224 & 0.225 & 0.227 & 0.230 \\
\hline
\end{tabular}

\section{Numeric analysis of fundamental natural frequencies of the aluminium/composite shaft}

Numerically determined fundamental natural frequency values of the hybrid shaft made of $2.5 \mathrm{~mm}$ thick aluminium tube and eight layers of carbon fibre/epoxy composites with the fibre orientation angle of $45^{\circ}$ (shaft length $1.35 \mathrm{~m}$, mean radius of the shaft $0.041 \mathrm{~m}$, the shaft supported on both ends) are presented in Figure 5. 


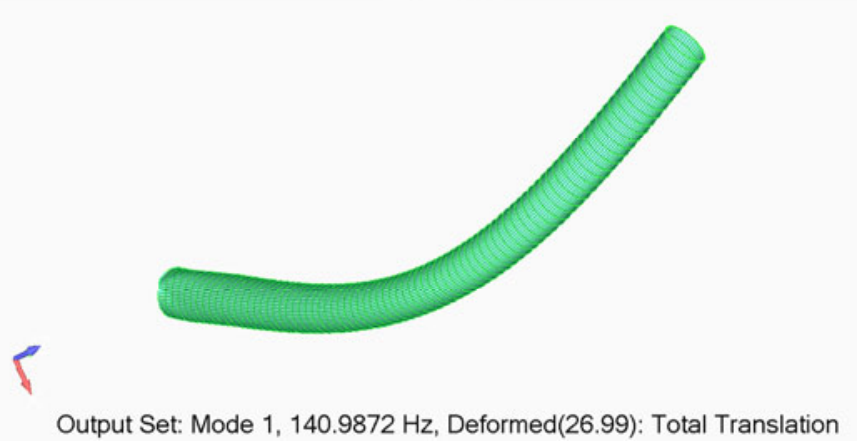

Fig. 5 Fundamental natural frequency of the hybrid Al/USN150 carbon fibre/epoxy composite shaft

Based on the fundamental natural frequencies values in the first vibration mode, $f_{\mathrm{s}}$, the critical rotational speed of the analysed shaft can be obtained by using the following expression:

$$
n_{k r}=60 \cdot f_{s}
$$

The values of the critical speeds obtained in this way are presented in Table 4 .

Table 4 Critical speed

\begin{tabular}{|c|c|}
\hline \multicolumn{2}{|c|}{ Critical speed, rpm } \\
\hline Aluminium/composite shaft $\mathrm{Al} /\left[ \pm 45_{\mathrm{USN}, 4}\right]$ & 8454 \\
\hline Steel & 8336 \\
\hline Aluminium & 8355 \\
\hline
\end{tabular}

Analysing the results obtained in the papers [4], [5], [7],[14], it can be concluded that natural frequency value decreases with an increase in the orientation angle of fibres. The results presented in Table 4 show that even when the fibre orientation angle is $\pm 45^{\circ}$, the natural frequencies of the hybrid aluminium/composite shaft have slightly higher values compared to a pure steel or aluminium shaft of the same dimensions (by about $1.5 \%$ ).

\section{Experimental analysis of the studied shaft}

An experimental analysis of the composite shaft stress state was performed in order to verify the results obtained by the numerical analysis. A scale shaft model with dimensions obtained by applying the similarity law was used. The real operating conditions were simulated. The method of the complete geometric proportionality means that all the geometric measurements change in accordance with the same length increase factor. The torque increase factor is expressed as a function of the length increase factor, so that the stress state remains unchanged. Table 5 gives basic dimensions and load values for the real shaft and the shaft model made for the experimental analysis.

Table 5 Basic dimensions of the real shaft and the shaft model

\begin{tabular}{|l|c|c|}
\hline \multicolumn{1}{|c|}{ Basic properties } & Real shaft & Model \\
\hline Outer shaft diameter & $85 \mathrm{~mm}$ & $21.8 \mathrm{~mm}$ \\
\hline Inner shaft diameter & $78 \mathrm{~mm}$ & $20 \mathrm{~mm}$ \\
\hline Composite layer thickness & $8 \times 0.125=1 \mathrm{~mm}$ & $4 \times 0.10=0.4 \mathrm{~mm}$ \\
\hline Aluminium tube thickness & $2.5 \mathrm{~mm}$ & $0.65 \mathrm{~mm}$ \\
\hline Shaft length & $1350 \mathrm{~mm}$ & $346 \mathrm{~mm}$ \\
\hline Torque & $5000 \mathrm{Nm}$ & $85 \mathrm{Nm}$ \\
\hline
\end{tabular}


A numerical analysis of the scaled shaft model was also performed and the results are similar to the values for the actual drive shaft.

As for the experimental analysis, the shaft model was made of aluminium combined with carbon fibre/epoxy resin with the fibre orientation angle of $\pm 45^{\circ}$. The stress was measured using $\mathrm{V}$ - shaped rosettes with grid axes at the angle of $\pm 45^{\circ}$ with respect to the longitudinal axis of the shaft. Strain gauges type 3/120 XY21, produced by HBM (Hottinger Baldwin Messtechnik), were used (Figure 6).

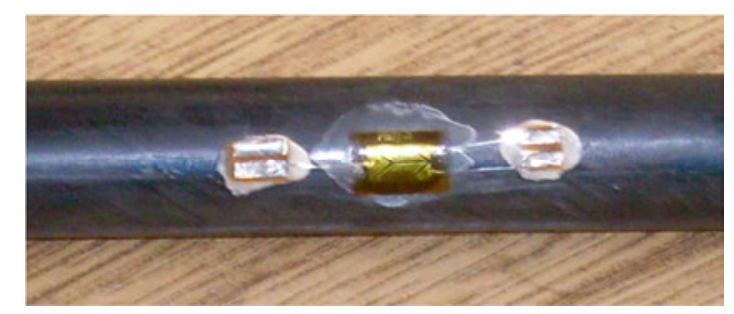

Fig. $6 \mathrm{~V}$ shaped rosettes

The studied shaft model with glued strain gauges is shown in Figure 7.

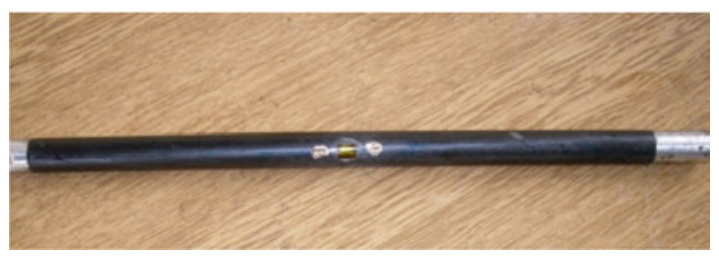

Fig. 7 The shaft model with glued strain gauges

The strain gauges were connected to the multi-channel measuring device UPM 60. This is a digital measuring device equipped with a microprocessor which performs a variety of functions (selection of measuring point, selection of measuring unit, numerical value display, etc). The CATMAN software was used for communication between the UPM 60 and the computer and it enabled adjustment and use of the measuring equipment.

Figure 8 shows the shaft model with glued and connected strain gauges, mounted on the testing device.

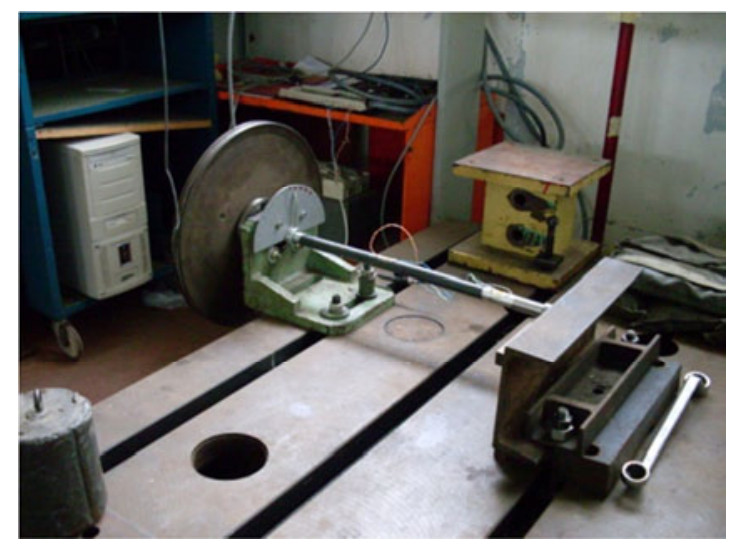

Fig. 8 The laboratory device for shaft torsion testing

The values of the measured strain gauge deformations $\varepsilon$ and the stress due to torsion are given in Table 6 . The same table gives numerically obtained values of stress due to shaft torsion. The last column gives errors between the experimentally and the numerically determined stress values. Since the error value is below 3\%, it can be concluded that there is a good agreement between the numerical and the experimental results. 
Table 6 Values of stress due to torsion obtained experimentally and numerically

\begin{tabular}{|c|c|c|c|c|c|c|}
\hline$F, \mathrm{~N}$ & $T_{\text {exp. }} \mathrm{Nm}$ & $T_{\text {num }}, \mathrm{Nm}$ & $\varepsilon, \mu \mathrm{m} / \mathrm{m}$ & $\begin{array}{c}\tau_{\text {exp }}, \mathrm{MPa} \\
\text { (experimental } \\
\text { value) }\end{array}$ & $\begin{array}{c}\tau_{\text {num }}, \mathrm{MPa} \\
\text { (numerical } \\
\text { value) }\end{array}$ & Error, \% \\
\hline 100 & 20 & 1180 & 890 & 35.7 & 35.0 & 2.0 \\
\hline 200 & 40 & 2370 & 1730 & 69.2 & 67.4 & 2.6 \\
\hline 300 & 60 & 3550 & 2650 & 106.0 & 103.1 & 2.7 \\
\hline 400 & 80 & 4700 & 3590 & 143.6 & 140.3 & 2.3 \\
\hline 425 & 85 & 5000 & 3810 & 152.4 & 148.5 & 2.6 \\
\hline
\end{tabular}

This agreement is very important because it demonstrates that the developed model is appropriate for the numerical analysis.

\section{Conclusion}

The primary objective of this paper was to analyse the stress state and calculate the critical rotation number of the shaft made of combining aluminium and composite materials by applying numerical and experimental methods.

An important advantage of composite materials in the manufacture of shafts is that they enable an increase in the drive shaft length without causing bending resonance. This paper analyses the possibility of using one composite drive shaft instead of two cardan shafts. The outer diameter of the shaft remains the same so that it can be mounted into the existing forks of the cardan joint.

Based on the obtained results, some advantages of the composite over the steel cardan shafts can be pointed out:

- the weight of the composite shaft made by combining aluminium and carbon fibres is reduced by about 3.5 times compared to the steel shaft of the same dimensions,

- $\quad$ higher power transfer, i.e. higher torque transfer capability is enabled,

- the limit values of the critical rotation number have been increased, i.e., the composite shaft can operate at a higher rotation speed compared to the steel shaft,

- the analysis of the stress state shows that composite shafts can adequately replace steel shafts,

- simpler construction is achieved.

Consequently, it can be concluded that composite materials should replace conventional materials in the manufacture of cardan shafts.

\section{Acknowledgement}

This investigation is a part of the project TR 33015 of the Technological Development of the Republic of Serbia and the project III 42006 of Integral and Interdisciplinary investigations of the Republic of Serbia. We would like to thank to the Ministry of Education and Science of the Republic of Serbia for the financial support during this investigation.

\section{REFERENCES}

[1] Lee, D.G., Kim, H.S., Kim, J.W., Kim, J.K., 2004. Design and manufacture of an automotive hybrid aluminum/composite drive shaft. Composite Structures, 63(1): 87-99. DOI:10.1016/S02638223(03)00136-3

[2] Shokrieh, M.M., Hasani, A., Lessard, L.B., 2003. Shear buckling of a composite drive shaft under torsion, Composite Structures, 55(1): 214-225. DOI10.1016/S0263-8223(03)00214-9 
[3] Gubran, H.B.H., Gupta, K., 2002. Cross-section deformation of tubular composite shafts subjected to static loading conditions, Mechanics Research Communications, 29(5): 367-374.DOI:10.1016/S00936413(02)00270-7

[4] Rastogi, N., 2004. Design of composite driveshafts for automotive applications, SAE World Congress, Detroit, Michigan. DOI:10.4271/2004-01-0485

[5] Gubran, H.B.H., 2005. Dynamics of hybrid shafts, Mechanics Research Communications, 32: 368-374. DOI:10.1016/j.mechrescom.2005.02.005

[6] Badie, M.A., Mahdi, E., Shamouda, A.M., 2011. An investigation into hybrid carbon/glass fiber reinforced epoxy composite automotive drive shaft, Mater Des, 32: 1485-500. DOI10.1016/j.matdes. 2010.08.042

[7] Mutasher, S.A., 2009. Prediction of the torsional strength of the hybrid aluminum/ composite drive shaft, Mater Des, 30(2): 215-20. DOI:10.1016/j.matdes.2008.05.024

[8] Abu Talib, A., Ali, A., Badie, M., Azida Che Lah, N., Golestaneh, A., et al., 2010. Developing a hybrid epoxy composite automotive drive shaft, Mater Des, 31(1): 514-21. DOI:10.1016/j.matdes. 2009.06.015

[9] Djordjevic, Z., Blagojevic, M., Marjanovic, V., Jovanovic, S., 2014.The influence of material types on twist angles and torsion stability of a composite shaft, Technical Gazette, 21(5): 917-923, ISSN 13303651

[10] Kojic, M., Slavkovic, R., Zivkovic, M., Grujovic, N., 1998. Method of finite elements I (in Serbian), Faculty of Mechanical Engineering, Kragujevac. [ISBN 86-80581-27-5]

[11] Djordjevic, Z., 2008. Dynamic conduct composite shafts (in Serbian), PhD Thesis, Faculty of Mechanical Engineering, Kragujevac, Serbia (in Serbian)

[12] Bathe, K.J., Dvorkin, E.N., 1986. A formulation of general shell elements - the use of mixed interpolation of tensorial components', Int. j. numer. methods eng.,22: 697-722. DOI:10.1002/nme.1620220312

[13] Ruzic, D., Maksimovic, S., Milosavljevic, D., 2003. Postbuckling response and failure analysis of layered composite structural components, Mechanics and Material Conference, USA.

[14] Djordjevic, Z., Govedarovic, J., 2004. Influence angle of fibres orientation on dynamic characteristics of composite shaft, Proceedings of the conference IRMES '04, Research and Development of Machine Elements and Systems, Kragujevac, Serbia, p. 637-642 [ISBN 86-80581-66-6].

Submitted: $\quad 28.01 .2016$

Accepted: $\quad 16.12 .2016$ dr Zorica Djordjević

zoricadj@kg.ac.rs

dr Mirko Blagojević

mirkob@kg.ac.rs

dr Snežana Vulović

vsneza@kg.ac.rs

dr Danijela Nikolić

danijelan@kg.ac.rs

dr Saša Jovanović

dviks@kg.ac.rs

University of Kragujevac, Faculty of

Engineering Kragujevac, Serbia 